\title{
La provisión de servicios en el puerto colonial de Montevideo: Alcances y limitaciones de una fuente local de riqueza*
}

\author{
Arturo Ariel Betancur \\ Universidad de la República. \\ Montevideo. Uruguay
}

En el presente artículo se desarrolla una proyección del suministro de distintos servicios en un puerto periférico del imperio español. Basado casi exclusivamente en documentación original procedente de los principales archivos rioplatenses, el trabajo contiene una amplia relación sobre esta temática específica. Las oportunidades ofrecidas en ese contexto han sido agrupadas, según su carácter. en empresariales y laborales. En ambos casos se encaran primeramente sendas instancias descriptivas, seguidas por informaciones acerca de sus rendimientos económicos. Aparecen continuos ejemplos de la variedad de casos y situaciones analizadas, sobre todo en lo que hace a retribuciones personales. Finalmente surgen con nitidez la diversidad y la conveniencia de las citadas prestaciones como generadoras de riqueza en la comunidad montevideana.

El puerto colonial de Montevideo alcanzó en los últimos 40 años de dominio español un creciente protagonismo, basado fundamentalmente en su situación geográfica. En sucesivas etapas se convirtió en terminal de buques correos, apostadero naval del Atlántico Sur, sede de oficinas administrativas específicas, destino de buques mercantes, corsarios y negreros, nudo de comunicaciones regionales, etcétera.

En torno de su recinto no cesaría de crecer a su vez una población de singular dinamismo. Mientras recibía inmigrantes trasatlánticos y de la región, progresaba en ella una plaza comercial incentivada por diferentes oportunidades. La mayor parte de éstas coincidieron con la guerra hispano británica iniciada en 1797. Allí se intermediaba en todo, se salaban muchas toneladas de carne, y bullía el espíritu mercantil estimulado por una apertura inestable pero generosa. En medio de una anárquica libertad a casi todas las naciones, se paliaba entretanto la situación financiera, muy deteriorada en un imperio cuya cabeza se iba desprendiendo del resto.

Hecha la paz con Gran Bretaña, habría variantes de relevancia en la coyuntura internacional. Los enemigos se volverían amigos y pronto susti-

* El presente trabajo se origina en el marco del proyecto titulado "El puerto de Montevideo en el Siglo XIX. Su articulación con la cuenca del Plata”, dirigido por el Dr. Juan A. Oddone, en el Departamento de Historia Americana de la Facultad de Humanidades y Ciencias de la Educación. 
tuirían de hecho a la metrópoli casi ausente. Esto y la lucha con Buenos Aires, frenarían considerablemente la multitud de oportunidades anteriores. Montevideo se aproximaría poco después a una crisis del mismo modo económica que política, y se reduciría casi a la nada.

Pero a lo largo de su corto vuelo había encontrado en el puerto la verdadera razón de existir. No sólo fue entrada y salida para todo, sino que también representó una fuente de oportunidades en sí mismo. Igual que partía para La Habana, la carne salada de su cinturón industrial halló una clientela cada vez más abundante entre las tripulaciones de los buques. Las emergentes figuras de su comercio pudieron invertir parte de sus caudales en adquirir embarcaciones fácilmente rentables y la creciente afluencia de inmigrantes halló pronta ocupación.

A reseñar esas oportunidades estarán destinadas las páginas que siguen. Una primera subdivisión del planteamiento nos muestra dos áreas bien definidas, según afectaran al ámbito empresarial o al del trabajo. En ambos casos, se procurará describir brevemente las diversas formas de beneficio generadas; también para las dos se analizará el alcance de la redistribución de riqueza operada, sus desigualdades y razones.

\section{Oportunidades empresariales}

\section{El abastecimiento de la Marina}

Su idoneidad portuaria transformó a Montevideo en sede de las fuerzas navales destinadas al extremo sur del imperio español de ultramar. Se estableció en él un apostadero, o sea un instituto orgánico encargado de atender con cierta autonomía la seguridad y la defensa de su ámbito, que tuvo como misión específica proteger las Islas Malvinas y el pasaje del Atlántico al Pacífico. Comenzada su actividad en 1769, con el arribo de la expedición de Juan Ignacio de Madariaga, siete años más tarde se definieron oficialmente sus funciones. Su dotación primitiva fue de dos corbetas, que se alternaban entre el Plata y el archipiélago austral, pero en los años siguientes la misma fue aumentando junto con la importancia del enclave.

En 1787 señalaba Pérez Castellano que se había agregado una fragata grande. Para fines del siglo XVIII, seguía progresando la armadilla que, según Mariluz Urquijo, comprendía tres corbetas, igual número de bergan- 
tines y una fragata, aunque casi todas ellas en muy mal estado. El mismo autor destaca también la existencia de un grupo de lanchas cañoneras. ${ }^{1}$

Las embarcaciones necesitaban distintos servicios, que la Junta de Marina contrataba en tierra por plazos generalmente quinquenales mediante el régimen de asientos. Esto significaba que durante el término establecido, el o los encargados tendrían la exclusiva absoluta del abastecimiento, bajo los precios y las condiciones pactadas. El suministro de víveres constituyó obviamente el de mayor volumen y relevancia.

Conocemos otras prestaciones subastadas por la Marina al margen del abastecimiento alimentario, y al igual que éste conferidas por lustros. En agosto de 1803 se remató el asiento de medicinas "simples y compuestas" para proveer las cajas de los bajeles de guerra que se habilitaban en Montevideo. ${ }^{2}$ Casi simultáneamente había concluido el plazo por el que a fines de 1795 se concediera el de herrería, cerrajería y calderería, que en agosto de 1802 se otorgó por un nuevo quinquenio. ${ }^{3}$ Otro acuerdo de relevancia fue el de velas de sebo destinadas a los buques reales, "tanto en este puerto como navegando". ${ }^{4}$

\section{a) Los asientos de víveres}

El antecedente más claro de este servicio hay que hallarlo en los llamados vivanderos. Mediante la provisión de alimentos a la guarnición militar, esos mercaderes ambulantes dieron vida a uno de los primeros renglones locales generadores de capital.

Un asiento de comestibles cumplido en los años 1770 por el múltiple empresario Francisco Medina, en consorcio con otros dos colegas, constituyó entretanto un ejemplo pionero de esta clase de contratas. Se trató del abastecimiento en esos renglones a la expedición militar comandada por Pedro de Ceballos, negociado con la propia Comandancia de Marina de Montevideo. ${ }^{5}$

1 Martínez Montero, Homero: Montevideo nació en el mar. Montevideo, 1977, págs. 43-48. Archivo General de la Nación (en adelante AGN), Archivos Particulares. Libro manuscrito, 1. Mariluz Urquijo, José M.: El virreinato del Río de la Plata en la época del Marqués de Avilés (1799-1801). Buenos Aires, 1987, págs. 115-117.

2 AGN, Protocolos de Marina. Fianzas de Buques, 1803-1804, fol. 79.

3 Ibídem, fol. 103. AGN, Ex Archivo y Museo Histórico, Caja 245, carpeta 31 y Caja 252, carpeta 35 a.

4 AGN, Ex Archivo y Museo Histórico, Cajas 241 y 245.

5 Archivo General de la Nación Argentina (en adelante AGNA), División Colonia, Sección Gobierno, Criminales, Legajo 26, expediente 20. 
En el quinquenio 1785-1789 se encargó del suministro al apostadero Francisco Antonio Maciel, cuya deficitaria atención impidió que se lo volvieran a conceder en 1794 y 1795. Le sucedió el también comerciante Manuel Vázquez, quien atendió el servicio durante toda la década de los 90, pues su buen desempeño en el primer período le valió la preferencia en la convocatoria siguiente. La entrada en el siglo XIX halló a Mateo Magariños como titular del asiento, en el que consiguió ser preferido en 1806 por un nuevo ciclo. Sorpresivamente lo transfirió entonces a José Batlle y Carreó, a quien tocaría afrontar en ese carácter los peores momentos de la época hispánica. Manuel Ximénez y Gómez y José Ramírez, completarían a su vez con pasajes breves los últimos dos años coloniales.

El núcleo de los suministros de esta clase estuvo en la reposición ("repuesto") de los víveres consumidos por los buques de guerra de armadilla durante el viaje de ida, y en la provisión cotidiana de raciones mientras permanecían anclados (la "diaria de puerto"). A las mencionadas se agregaban las embarcaciones al servicio de la plaza de Montevideo, las de la carrera de la costa patagónica, los bajeles guardacostas, y por último se incorporaron también los de correos. Era obligación del asentista mantener "bien acondicionadas", en almacenes ubicados dentro de la ciudad, "prontas y listas siempre", un número elevado de raciones. En 1794 eran 20.000 , pero a partir del período siguiente pasaron a ser 50.000. ${ }^{6}$ Las mismas se componían de alimentos frescos o desecados, según se las destinara al consumo inmediato o para las travesías, como asimismo de leña rajada, o carbón. En ambos casos existía la llamada ración de dieta, con gallina en vez de tocino o carne (salada para el primero, fresca para el segundo), cereales y "pasto necesario". Igualmente se operaban diferencias en los suministros de Cuaresma y Semana Santa, con predominio del pescado seco. ${ }^{7}$

Los productos panificados tenían singular importancia y los comerciantes de ese renglón poseían por tanto el mayor interés (Magariños y Batlle estaban ligados al negocio, lo mismo que Miguel Zamora, quien los había proporcionado durante cuatro de los cinco años de vigencia del contrato de Vázquez, y asociado con Maciel se postuló al remate de 1794).

6 AGN, Archivos Particulares, Caja 105, carpeta 7. "Relación de los méritos, servicios y ejercicios literarios del Doctor Mateo Magariños". Madrid, 10 de octubre de 1817, pág. 4. AGNA, División Colonia, Guerra y Marina, Legajo 22, expediente 26.

7 AGNA, Ibídem. 
Esta se hallaba entre las razones que anotaba Pérez Castellano en 1795 para explicar la prosperidad de los panaderos por "sólo el rendimiento del bizcocho" destinado a los barcos. ${ }^{8}$

La Real Hacienda presentó en este punto un nivel de exigencias bastante alto. Las condiciones en que se ofreció la contrata en 1794 establecían, por ejemplo, que todo alimento no hallado de recibo se entregaría a la cárcel pública con los correspondientes descuentos. El pan sería a su vez necesariamente de harina, "y no de asemite u otros bodrios". Las fianzas debían pertenecer a sujetos "lisos, legos, llanos y abonados", con preferencia absoluta de las que se ofrecían en dinero efectivo. ${ }^{9}$

En 1812, se pedía que el pan fresco de diaria no fuera "ni muy pesado ni muy ligero y bien fermentado", siendo elaborado "de toda harina de trigo de buena calidad, con extracciones de afrechos y no exceder(í)a de tres libras de peso" cada pieza. El asentista sería sometido al reconocimiento de los peritos de abordo, en éste como en los otros productos que suministrara. Las reses destinadas a carne fresca deberían ser novillos de más de tres años, con la mejor calidad que permitiera cada estación, "no cansados", "sacados a lazo" y muertos a cuchillo. ${ }^{10}$

\section{b) Incumplimientos recíprocos}

La Comandancia de Marina justificaba en 1812 su perfil exigente en materia de productos panificados, por la experiencia adquirida a través de "algunos proveedores". Se había comprobado el empleo de trigos y otros granos de mala calidad, que producían "mal gusto y mal olor a la galleta, aceleran(do) su corrupción". ${ }^{11}$

El asentista que registró mayores faltas fue Francisco Antonio Maciel, al punto de ser rechazadas por ello sus ventajosas ofertas de 1794 y 1795. Las jerarquías navales recordaban por ejemplo los 18 meses de riguroso arresto por su complicidad en delitos de corrupción. Ello "sin que se le permitiese comunicación alguna, de que se seguía a la Marina el más mal servicio". Asimismo se le acusaba por la mala calidad de los víveres, especialmente grave en alta mar. Evocaban inclusive haber recibido una severa

8 AGN, Ex Archivo y Museo Histórico, Caja 240, carpeta 3 y Archivos Particulares, Libro manuscrito 1 , pág. 37.

9 AGNA, División Colonia, Guerra y Marina, Legajo 22, expediente 26.

10 AGN, Ex Archivo y Museo Histórico, Caja 315, carpeta 92.

11 Ibídem. 
advertencia del ministro Valdés por el estado de inútiles en que llegaban frecuentemente los alimentos para Cádiz. ${ }^{12}$

También se generaron dificultades para los asentistas, dentro de las cuales deben incluirse los propios incumplimientos de la Real Hacienda. Un largo pleito llevaron adelante ya Francisco Medina y sus socios, a raíz de los que estimaron perjuicios evidentes en su pionera contrata. El núcleo del contencioso radicó en no admitírseles como raciones completas 10.000 reses y ciertas cantidades de harina suplidas en su lugar. La controversia se prolongó más allá de la vida de ellos y el dictamen favorable a sus reclamaciones se conoció dos décadas después de ejecutado el servicio. ${ }^{13}$

Pero los mayores perjuicios fueron experimentados sin duda por José Batlle y Carreó. Sobre sus espaldas confluyeron las tres formas de los apuros más usuales: las dificultades para la compra de insumos de procedencia agrícola, las turbulencias políticas y, en parte como consecuencia de éstas últimas, la falta de pago por los suministros.

Las compras de trigo ocasionaron la mayor preocupación en casi todos los casos. Según estimaciones de Magariños, se necesitaban de 4.000 a 4.500 fanegas anuales, con un costo superior a 50.000 pesos en los momentos más adversos. Volúmenes estos que debían adquirirse "en las estaciones oportunas" a fin de comprar con más ventaja, y en la ciudad de Buenos Aires, por tratarse del "principal mercado" cerealero. Allí "siempre y por una razón necesaria, e(ra) más barato que en esta de Montevideo", donde por otra parte no existía suficiente producción.

Magariños padeció con la carestía del trigo en 1804, cuando se produjo una "escasez de granos que en muchos tiempos no se ha(bía) conocido igual". Pero Batlle debió afrontar esta dificultad prácticamente a lo largo de todo su desempeño, como consecuencia de la excepcionalidad del período. Los precios se elevaron enseguida, "por las ocurrencias políticas que sobrevinieron a los pocos días de haber principiado el despacho de raciones por (su) cuenta". Hicieron que "en lugar de haber tenido aquella prudente utilidad que según se calculaba, ofrecía el remate de la contrata..., perd(iera) (su) crecido caudal, el giro de (sus) negocios y de consiguiente el crédito".

Efectivamente, apenas hecho cargo del asiento, se produjo la toma de Buenos Aires por los británicos, que le ocasionó la pérdida de 3.000 fane-

12 AGNA, División Colonia, Guerra y Marina, Legajo 22, expediente 26. AGN, Ex Archivo y Museo Histórico, Caja 241.

13 Ibídem, Sección Gobierno, Criminales. Legajo 26, expediente 20. 
gas de trigo compradas allí. Al año siguiente, ocupada Montevideo, los agresores causaron graves daños en su establecimiento de la Aguada. Retirados los invasores, las alteraciones de 1808 aumentaron sus gastos y el volumen de los suministros exigidos por el estado de continuo sobresalto que atravesó la vida local. Los sucesos de 1810 profundizaron esta situación, con un activo bloqueo que demandó cada vez más provisiones, a la par que le cerraba la posibilidad de acceder por abastecimientos al mercado bonaerense. Completaron su desdicha los dos sitios puestos a la población, en cuyo intermedio pudo comprobar cómo su planta elaboradora se convertía en escombros, y la casa contigua era "plan barrido".

Por último, el "exacto cumplimiento del pago por la Real Hacienda en cada uno de los trimestres o cuatrimestres vencidos" había sido considerado por Batlle el único punto a favor del asentista. Pero, por las razones expuestas, esa previsión "jamás tuvo cumplimiento en todo el tiempo de su contrata, pasando muchos meses y aún años, para cobrar alguno". El primer retraso en las asignaciones coincidió con la ocupación inglesa, y se extendió por más de un año. Desde entonces se produjo un comprensible aumento de la morosidad, acrecentado en 1810 por la pérdida de la capital. Unicamente le fue posible rescatar sumas parciales, "a picos y a fuerza de súplicas, para satisfacer a los acreedores que más apuraban”. Con el correr del tiempo se agregaron al "debe" las prometidas indemnizaciones, su transformación en deudor de muchos miles de pesos, y una larga gestión de cobro en la propia corte, no culminada en el resto de su vida. Por tanto, para él, la oportunidad del asiento fue tan sólo "causa de enormes pérdidas", tal como recordaría con pesar en $1844 .{ }^{14}$

\section{c) Interés siempre renovado}

A pesar de todo lo anterior, nunca dejó de haber interesados en prestar el servicio. Fueron señaladas las pujas y aún las rebajas en las ofertas, dado que la participación en el negocio abría puertas a otras especulaciones.

En 1794, Manuel Vázquez partió de un ofrecimiento inicial de 36 maravedíes por ración, frente a 28 de los otros oferentes Maciel y Zamora. Ambas partes disminuyeron luego sus postulaciones, a 31 y 25 maravedíes, aunque ésta última fue rechazada por inadmisible ("sabe esta Junta el pre-

14 AGN, Protocolos de Marina, Registro de Protocolizaciones. Escrituras, año 1804, fols. 55 a 68. "Memorias de don José Batlle y Carreó" en Revista Histórica. Montevideo, tomo VII, págs. 148, 149, 155, 156, 159, 160, 161, 402, 406, 410, y 425; tomo VIII, págs. 49 y 67. 
cio a que puede darse la ración para que el triste que la disfruta no padezca para siempre"). A pesar de esto y a la supuesta imposibilidad del primero para disminuir su oferta (a menos que "dejar(a) (su) familia expuesta a mendigar"), hubo aún mucho margen para ello. ${ }^{15}$

Repetida al año siguiente la subasta, ambas partes igualaron en 23 maravedíes, con el resultado que ya se indicara. ${ }^{16}$ Mateo Magariños reduciría aún más esa suma, al rematar para el siguiente período por 20 maravedíes. El mismo asentista renunciaría poco después a abastecer los buques correos por considerarlos "unos surtimientos de puros repuestos" y de "flaca entidad". Hecha una nueva convocatoria separada, bastó que surgieran otros postulantes para que el titular resolviera proseguir con la prestación casi sin alteraciones. ${ }^{17}$

A pesar de los antecedentes negativos, también en la convocatoria de enero de 1812 se reiteró el interés por prestar el servicio, en este caso mediante la puja de José Ramírez y el nombrado Ximénez, a la postre adjudicatario. El primero incrementó en un $20 \%$ el nivel de los precios asignados por los convocantes y el segundo un 19\%. La competencia empujó a ambos hacia valores más bajos, hasta que finalmente el ganador se situó en $15 \% .^{18}$

Magariños señaló en 1804 la mayor conveniencia del abastecimiento de víveres, fuera de la moderada ganancia que sin dudas proporcionaba mientras los mercados no se sacudieran por situaciones extraordinarias. Fundando su citada decisión de continuar con el suministro a los buques correos, admitía que "a su sombra" ("causado del asiento") había conseguido ensanchar significativamente el giro de su casa comercial. ${ }^{19} \mathrm{La}$ entrada y salida de embarcaciones mercantes o corsarias en el puerto, representaba la eventualidad de un ingreso suplementario, fundamental para los sucesivos asentistas oficiales, máxime contando con todas las facilidades, instrumentos e instalaciones necesarias.

Este servicio constituyó sin duda una oportunidad empresarial de consideración, sobre todo por lo que representaba su extensión en el hirviente ámbito portuario montevideano. A quienes eran activos comerciantes, significó una posibilidad muy cierta de ventas fijas con la opción de ir per-

15 AGNA, División Colonia, Guerra y Marina, Legajo 22, expediente 26.

16 AGN, Ex Archivo y Museo Histórico, Caja 241, carpeta 27.

17 Ibídem, Protocolos de Marina, Registro de Protocolizaciones, 1804, fols. 55 a 68.

18 Ibídem, Ex Archivo y Museo Histórico, Caja 315, carpeta 92.

19 Ibídem, Protocolos de Marina. Registro de Escrituras correspondientes al año de 1804, fols. 55-60. 
manentemente a más. Pero también fue una fuente de riesgos, en la medida que tuvo como contraparte a la Real Hacienda. La suerte de estos empresarios estuvo estrechamente unida a la de aquella en el terreno financiero, lo que se volvió dramático a partir de 1806 cuando ingresó en una crisis sin retorno.

\section{El transporte marítimo y fluvial}

En este punto se hace necesario distinguir según se trate de la navegación de altura o de las embarcaciones menores que conformaban el llamado tráfico costanero del río. Mientras en el primer nivel nos hallamos con los integrantes de la élite local de actuación múltiple, en el segundo generalmente se trata de pequeños empresarios individuales dedicados a una actividad de subsistencia.

El negocio naviero mayor parece haber sido el más productivo de cuantos servicios pudieron encararse. Fue legalmente posible a partir de la autorización de 1796 para emplear buques pertenecientes a comerciantes no metropolitanos en cualquier tipo de expedición. Ello no significa que sólo desde entonces hubiera empresarios navieros montevideanos, pues en los años 1780, por ejemplo, tenían barcos propios Francisco Medina y Manuel Diago.

Mucho más importante aún fue poseer medios financieros y oportunidades efectivas para el tráfico. Ambas circunstancias deben considerarse derivadas de la nueva situación de apertura hacia la región y el mundo (comercio de ensayo, con neutrales, de esclavos, etcétera). Se conformó asî una flota de consideración, inclusive con naves de 400, 500 y hasta una de alrededor de 800 toneladas.

Los navieros locales fueron los mismos comerciantes e industriales, en algunos casos también hacendados, que cargaron sus producciones y mercancías. Pero igualmente procuraron rentar una parte de sus bodegas, estimulados por los altos precios de los fletes. Era muy raro que un cargamento de ida o de vuelta sólo perteneciese a un remitente. La excepción fue el tráfico de esclavos, pero aún ahí se podía observar algunas veces la diversidad de interesados.

Dado el bajo costo de los barcos en el exterior y las oportunidades que brindaban, por ejemplo, los remates de presas corsarias en casi todas partes, el peso de los fletes aparece exorbitante, sobre todo hasta 1806. En 
1797, una zumaca cuya compra se había contratado en Brasil por dos cuentos (millones) y 800.000 reis, en caso de no concretarse el negocio cobraría por transporte más de la mitad de esa suma: un cuento y 600.000 reis. ${ }^{20} \mathrm{La}$ reparación de una corbeta angloamericana de 138 toneladas insumió en 180517.000 pesos a sus compradores locales. Fletada de inmediato a Bilbao, les produjo una ganancia superior a 26.000 pesos, con lo que también fue cubierto el precio de 9.000 pesos desembolsado inicialmente. ${ }^{21}$

Mateo Magariños compró por 10.000 pesos en 1806 una fragata portuguesa y rápidamente reembolsó 8.500 producidos por sus propios fletes a Europa. Por ese entonces se cobraba de 40 a 42 reales la pesada de cueros en esa dirección, mientras que barcos de 400 y 500 toneladas redituaban hasta 40 y 50.000 pesos por viaje. "Los fletes eran subidos en nuestros puertos, y se apetecían los buques, y siempre había frutos que sacar", afirmaba tiempo después en magnífica síntesis retrospectiva, un comerciante de la ciudad de Lima. "Reportaban unos lucros terribles" y "los navieros hacían unas ganancias de gravedad" añadían otros en la misma ocasión..$^{22}$

En 233 pesos diarios o 7.000 al mes calculaba aún en 1811 un jefe de la Real Hacienda montevideana el precio de los servicios de una fragata que estaba cargando con destino al puerto de El Callao. ${ }^{23}$ Por tanto, poseer uno o varios barcos producía ganancias muy importantes, capaces inclusive de compensar las pérdidas que también eran frecuentes.

Sin duda sería mucho menos remunerativo el tráfico de embarcaciones menores, que se desplazaban en el Río de la Plata, hacia Buenos Aires u otros destinos cercanos y también intervenían en las propias operaciones portuarias de enlace entre buques y carretillas. La importancia de esta segunda flota era subrayada a comienzos del XIX por el propio capitán del puerto, que la consideraba un plantel permanente de buena marinería. Fijaba en ocho o nueve millones de pesos el volumen de frutos y efectos ingresados o extraídos por ella cada año. ${ }^{24}$

Ese "tráfico costanero" registraba en 1813, 147 pequeñas embarcaciones, de las cuales casi la mitad (65) eran balandras, seguidas a razón de 20 en cada una por goletas y zumacas. El resto se componía de 13 chalu-

20 Ibídem, Escribanía de Gobierno y Hacienda. Caja 34, expediente 53.

21 "Memorias de don José Batlle y Carreó". Revista Histórica, tomo VII, pág. 665.

22 Ibídem, Archivos Particulares, Caja 106, carpeta 7.

23 Ibídem, Ex Archivo General Administrativo, Libro 528.

24 Fernández Saldaña, José M.: Historia del puerto de Montevideo. Primera parte. Desde la época colonial hasta 1887. Montevideo, 1939, pag.36. 
pas, seis botes (dos de ellos de pescadores), cinco lanchones, cuatro lanchas, tres bergantines, tres faluchos, dos polacras, dos lugres, dos chalanas, un místico y un champán. ${ }^{25}$ La dinámica de estos bajeles de menor cuantía era importante, al punto que hubo días, en septiembre de 1812, de fondear hasta 27, en lo que sin duda fue una marca excepcional. Pero también hubo jornadas de siete, nueve y doce desembarcos, todos con distintos abastecimientos procedentes del interior del territorio. ${ }^{26}$

El negocio naviero en gran escala fue a todas luces de elevado rendimiento económico, aunque también comportaba un riesgo considerable en medio de tiempos tan agitados. Menor repercusión de ambos aspectos se registró en cambio a nivel del segundo tipo de tráfico, más una actividad de subsistencia que una posibilidad de enriquecimiento. De todos modos, tanto una como otra flota contribuyeron a la dinamización del cuerpo económico y del puerto montevideanos.

\section{Oportunidades laborales}

\section{La "gente de la mar"}

Fue amplio el espectro laboral que se vinculó con las actividades económicas generadas en torno al puerto. Lo más específico fue el "ejercicio de la mar", desempeñado entre otros por la clase de "hábiles dispersos", como se denominaba en Cádiz a una amplia franja de su matrícula. Gente de dura existencia, fue llamada en 1810 por un viejo conocedor de ella, la que "a precio de su tranquilidad y con riesgo de la vida, (ib)a a ganar un pan para sus hijos". ${ }^{27}$

Comprendía fundamentalmente al personal embarcado: capitanes, pilotos, contramaestres, marineros, cocineros, despenseros, pajes, mozos, etcétera. En un segundo nivel debe incluirse a prácticos, escribanos, cirujanos, y hasta capellanes, cuya presencia no era de la universalidad de aquellas plazas.

El papel de los capitanes fue obviamente fundamental. Su condición casi inseparable de primeros pilotos los transformaba en los grandes responsables de la navegación, seguidos también en ello por sus segundos. Ese

25 AGN, Ex Archivo General Administrativo, Libro 97.

26 Ibídem, Archivos Particulares, Caja 334, carpeta 3.

27 Ibídem, Ex Archivo y Museo Histórico, Caja 252, carpeta 35 a, y Caja 292, carpeta 73. 
compromiso se ponía de manifiesto en caso de perder la embarcación, lo que generaba profundas investigaciones y hasta podía acarrearles penas graves, impuestas por las jerarquías marítimas. Lo delicado de su función hacía que fueran muy exigentes las autoridades navales para habilitar a los encargados de la conducción de buques. Un "piloto aprobado" catalán invocaba en 1792 el examen rendido ante los maestros de la Academia de Barcelona. A su vez cierto aspirante rioplatense viajó en diciembre de 1805 desde Buenos Aires a Montevideo, "con el designio de examinarse en clase de piloto, ...según ordenanza". No se le expidió entonces el respectivo nombramiento por entenderse que "carec(ía) de los principios de la náutica" ${ }^{28}$ No obstante, el simple conocimiento empírico también constituyó una credencial esgrimida no sin éxito en ese ambiente.

Dentro del personal que embarcaba sólo a veces, sobresalían los prácticos. Básicamente se trataba de conocedores empíricos de las vías acuáticas y de las terminales, los que eran incorporados para evitar los riesgos en zonas desconocidas por los pilotos. "Me contraté en clase de tal práctico y en su virtud se me ordenó que condujese la fragata a este puerto", declaraba en agosto de 1804 un marino portugués ajustado al efecto en Santa Catalina. El capitán, a su vez, dijo haberle "entreg(ado) el buque" a este entendido y "el gobierno y dirección de la fragata" a otro colega que le sustituyó. Con todo ello complementaba una definición de la actividad y de las atribuciones consiguientes. Lo suyo consistía en indicar la naturaleza del itinerario, y más específicamente las características del fondo, los bancos y las corrientes. ${ }^{29}$

Era muy común que una vez dentro del río se procurara contratar un práctico en Maldonado para seguir adelante. Sobre todo lo requerían aquellos marinos extranjeros que se aventuraban por primera vez en sus aguas. Quienes sabían cómo llegar hasta Montevideo, pero su destino final era Buenos Aires, no se arriesgaban en la difícil travesía intermedia sin obtener aquí el concurso de alguno de estos "baqueanos fluviales". Su intervención en las operaciones de entrada y salida al puerto era irrecusable. Haber ingresado un buque sin necesidad de práctico, era invocado en 1800 por un piloto como mérito excepcional, equiparable al "más riguroso examen". ${ }^{30}$

\footnotetext{
28 Ibídem, Caja 237, carpeta 6, y Caja 264, carpeta 47.

29 Ibídem, Caja 257, carpeta 40.

30 AGNA, División Colonia, Comerciales, Legajo 20, expediente 18.
} 


\section{Servicios suministrados desde tierra}

El proceso de carga y descarga fue una importante brecha para la generación de lugares de trabajo. Aparte de la segura participación de mano de obra esclava, en los testimonios portuarios hay mención frecuente a la existencia de peones, y más concretamente a estibadores de cueros. Realizadas prácticamente sobre la base de la fuerza humana, esas tareas fueron prolongadas y complejas. En el período final de la plaza se dispuso conformar una matrícula de "los individuos estibadores" que requerirían del permiso gubernamental para emplearse "en el abarrote y estiba de cueros".

Era de gran importancia para estas maniobras el tránsito de las llamadas carretillas. Con ellas, "tiradas de hombre o de animales" como se diferenciaba en un documento de la época, ${ }^{32}$ se cubría la distancia entre el muelle y los almacenes de origen o destino de las cargas. Vehículos más pequeños y ágiles que las carretas, fueron arrastrados generalmente por caballos, bueyes o mulas. La cantidad de carretillas destinadas sólo al ámbito portuario era importante, aunque en 1811 un jefe de rentas se quejaba de su escasez. En un reglamento aprobado ese mismo año se establecía su número en 80 , mientras el gremio por entonces en formación se comprometía a mantener constantemente medio centenar, e incrementarlo cuanto fuera necesario. ${ }^{33}$

Las reparaciones marinas tuvieron también relevancia. La carena de buques en los puertos es connatural al tránsito de los primeros y a la propia existencia de ambos. Como punto muy frecuentado, Montevideo reunió apreciable cantidad de expertos en esa clase de trabajos. En 1813, carpinteros y calafates sumaban un centenar, pese a que casi no existía actividad portuaria como consecuencia de la situación bélica. Hasta 1812 ambas profesiones se hallaban comprendidas en el régimen de matrículas, obligatorio para los integrantes de los respectivos gremios. En 1803, se objetaba la participación de un carpintero en ciertos trabajos, por falta de la respectiva constancia de hallarse matriculado en este puerto. De todos modos se equiparaba ese trámite con el de resultar "apto para ejercitarse en las citadas obras", lo que quita rigidez a la indicada figuración. ${ }^{34}$ En 1813, extinguidas

31 AGN, Archivos Particulares, Caja 105, carpeta 3, fols. 16-18.

32 Ibídem, Caja 334, carpeta 4, fol. 89.

33 Ibídem, Ex Archivo General Administrativo, Libro 477, fols. 46-48, Archivos Particulares, Caja 334, carpeta 4, fols. 86-90.

34 AGNA, División Colonia, Consulado de Buenos Aires, Legajo 5, exped. 7. 
aquéllas por disposición real, se abrió un registro oficial, que dio como resultado la suma indicada.

El trabajo de ambas especialidades tenía lugar indistintamente en tierra (lo que diera lugar a la expresión "carpintero de ribera", o "los que no navegan"), y a bordo de las embarcaciones, fuera que éstas se hallaran en puerto o en tránsito. La administración les requería contínuamente para efectuar reconocimientos, informes y obras en las más diversas circunstancias de la vida portuaria.

La fabricación de buques, sin duda conectada con este tema, no tuvo lugar en forma sistemática, fundamentalmente por la falta de maderas apropiadas, que en la región sólo tenían Paraguay y Corrientes. En marzo de 1809 un anónimo escritor analizaba con esperanza las posibilidades del Río de la Plata para un eventual desarrollo de la citada industria. Entre las potencialidades enumeradas figuraba la fertilidad de las márgenes del estuario para el cultivo del cáñamo. Más de un cuarto de siglo antes se habían avanzado en Montevideo ensayos serios precisamente en esa dirección. Estuvieron a cargo de José Reguera, que en 1782 había llegado en clase de poblador desde La Coruña, y de inmediato comenzó a desempeñar su oficio de corchador de jarcias. Según la antigua fórmula, "a su costa y minción" condujo desde Chile semillas de cáñamo, que plantó en tres parajes diferentes con suerte también variada. En 1791 fracasaron entretanto sus gestiones para el logro de 150 cuadras de campo adecuado para el cultivo, sobre la desembocadura del arroyo Pantanoso, aún después de haber tomado posesión formal del mismo. ${ }^{35}$

Los servicios de sanidad se organizaron en Montevideo a consecuencia de la preocupación que generó el masivo ingreso de esclavos desde los primeros años 1790. Como culminación se creó en 1804 una Junta de Sanidad que convirtió al enclave en "filtro" de la región. Los médicos José Giró y Juan Cayetano Sánchez de Molina, vocales de la indicada corporación, conjunta o separadamente tuvieron a su cargo las visitas, de que no estaba exento ningún buque. ${ }^{36}$

Cuando las enfermedades se habían generalizado a bordo, disponían cuarentenas e incomunicaciones por períodos variables. Dado el riesgo que entrañaba la falta de cumplimiento de las medidas, se llegó a disponer

35 Ibídem, Guerra y Marina, Legajo 18, expediente 26. Tribunales Administrativos, Legajo 9, expediente 246 .

36 AGN, Archivos Particulares, Caja 246, carpeta 7, págs. 1-8, y carpeta 11, pág. 25. 
"pena de la vida" a quienes las transgredieran ${ }^{37}$ Los facultativos también administraban el suero antivariólico, si los esclavos aún no habían sido vacunados, condición esta última indispensable para su posterior venta. ${ }^{38}$

Una función en algo asimilable a la anterior, se instaló un tanto tardíamente. Era ejercida por cierta especie de cronista portuario, que divulgaba en tierra y por escrito las novedades de interés comercial generadas a bordo de los buques mercantes y distribuía rápidamente a sus suscriptores, las papeletas con el detalle de los cargamentos que ingresaban, o con las disponibilidades de los que se preparaban para partir. Fue autorizada en Montevideo a comienzos del siglo XIX, con lo que se trasladaba a la rada local una institución ya existente en Cádiz y otras terminales de la Península. ${ }^{39}$

Una suerte de servicios accidentales ofrecieron intérpretes y buzos. Los primeros eran requeridos sólo en caso de arribar buques extranjeros, y los segundos aún con menos frecuencia, al producirse naufragios con hundimientos de valores. La circunstancialidad de éstos últimos era doble, ya que por lo general su presencia en Montevideo obedecía al hecho de integrar la tripulación de algún barco estacionado en la bahía.

Impensable o muy rara antes de los años 90, la necesidad del intérprete en las operaciones portuarias fue una consecuencia del proceso de apertura mercantil y el plantel de entendidos montevideanos en esta tarea se fue conformando un tanto al azar. Los primeros y naturales "lenguas" fueron los militares, ya que es sabido cómo el ejército hispánico contó siempre con alto número de efectivos extranjeros. Pero fue la penetración foránea la que suministró luego la mayor parte. Al mercader catalán Pedro Sagrera, vecino de Montevideo, le fue expedido título oficial de intérprete y traductor en 1808. Se definía su función como la de alguien que traducía los papeles, oficios o documentos que se presentaran al gobierno. ${ }^{40}$

También en forma circunstancial los buques requirieron todo otro tipo de servicios desde tierra, siendo quizá los más frecuentes de faroleros, herreros, toneleros, cerrajeros, maestros de velas, etc., etc. Asimismo, adquirió importancia la custodia y el mantenimiento de embarcaciones que por alguna razón debían permanecer detenidas en la bahía. Por último, en

37 Ibídem, Ex Archivo General Administrativo, Libro 95.

38 Ibídem, Escribanía de Gobierno y Hacienda, Caja 39, expediente 30.

39 Ibídem, Caja 105, expediente 1.

40 AGNA, División Colonia, Tribunales Administrativos, Legajo 25, expediente 805. 
una matrícula del comercio redactada en 1812, se incluían dos corredores de número, sin que surjan más datos de su actividad. ${ }^{41}$

\section{La remuneración del trabajo}

En 1810, un capitán español desistía de intentar el salvamento de su buque por "lo costoso que e(ra) aquí el trabajo del hombre". ${ }^{42}$ A su vez otros observadores en diferentes momentos se refirieron a Montevideo como un puerto "caro". Sin embargo, a la mayor parte de la gente empleada allí, o a través de él, no se la agrupaba en otra categoría que la de seres sufrientes. Francisco Juanicó llamaba infeliz y desdichado a un capitán de barco, sin otros bienes que "su probidad y su pericia". ${ }^{43}$ Seguramente con más razón se evocaba en algún lugar como "hombres infelices" a los carretilleros y en particular a los tripulantes de una embarcación portuguesa contratados por salarios bajísimos. ${ }^{44}$ Un carpintero decía a su vez hallarse "en deplorable estado", sin ropas e impedido de auxiliar a su "pobre familia". Mientras tanto un comerciante local definía a los de este último oficio genéricamente como míseros artesanos, subordinados además a "una perfecta esclavitud", "pendiente del arbitrio del ingeniero" que organizaba el trabajo; decía "si un accidente les separa(ba) de su gracia, les e(ra) de absoluta necesidad o perecer o mudar de país, o entregarse a diferente ocupación" ${ }^{45}$

El capitán de una fragata extranjera denunciaba a su vez, en julio de 1811, la deserción de dos hombres, "que tenía trabajando por sólo la comida". ${ }^{46}$ También por esta, y en régimen de media ración, desempeñaron algunas tareas ocho hombres embarcados "sin plaza" a fines de 1809 en el correo "Diamante", que hacía viaje a Montevideo ${ }^{47}$ En general no existía seguridad en el trabajo, eran frecuentes los despidos, y aún los desconoci-

41 AGN, Escribanía de Gobierno y Hacienda, Caja 103, expediente 122.

42 Ibídem, Caja 96, expediente 171.

43 Ibídem, Ex Archivo y Museo Histórico, Caja 264, carpeta 47, y Caja 292, carpeta 73. AGNA, División Colonia, Comerciales, Legajo 20, expediente 18.

44 Ibídem, Ex Archivo General Administrativo, Libro 569, fol. 5v., y Ex Archivo y Museo Histórico, Caja 251, carpeta 35.

45 Ibídem, Ex Archivo y Museo Histórico, Caja 257, carpeta 40. AGNA, Consulado de Buenos Aires, Legajo 5, expediente 7.

46 Ibídem, Protocolos de Marina, Registro de Protocolizaciones, Legadillo de Protestas, 1811-1814, fol. $29 \mathrm{v}$.

47 Ibídem, Archivos Particulares, Caja 334, carpeta 4. 
mientos de contratos. La guerra constituía una causa autorizada para prescindir inclusive de los más altos oficiales de abordo. Los marineros eran abandonados muchas veces lejos de su tierra por las tripulaciones extranjeras, que los embarcaban por exigencias legales.

Las mayores remuneraciones fueron percibidas por los que hemos llamado servicios accidentales, muy especialmente los buzos, dada la excepcionalidad de su intervención. La pérdida de la fragata española "La Baronesa", a comienzos de 1810, generó una sorprendente oportunidad de ganancia para tres de ellos, que rescataron lo más valioso del cargamento. A las nueve de la mañana del ocho de febrero, poco después de producirse el hundimiento de la embarcación dentro del puerto, el capitán celebraba el respectivo contrato. El trío de buceadores "trabajaría debajo del agua lo que pu(dier)a, hasta libertar los caudales de su registro, que en tres cajones exist(1́a)n en la Santa Bárbara" de la misma. De tener éxito, se les retribuiría con un cajón de plata, cuyo valor en efectivo era de 3.000 pesos fuertes. A las cinco de la tarde la faena terminaba, después de haber "trabajado infatigablemente". Al día siguiente recibieron los beneficiarios el premio establecido, y de inmediato adquirían por 1.300 pesos el casco del buque. Los buzos, pertenecientes a la dotación de la fragata "La Proserpina", fueron interesados asimismo para recuperar una partida de cobre perteneciente a la carga. ${ }^{48}$

Muy diferente había sucedido a los colegas suyos que actuaron en el hundimiento de la fragata española "Nuestra Señora del Buen Viaje" con toda su carga, en noviembre de 1789. Cuatro buzos rescataron de las aguas 376 fardos, por los que habían convenido percibir también la tercera parte. Pero sólo cobraron a los seis años, después de liquidar y reliquidar varias veces las cifras ganadas, de ausentarse los interesados en sus buques, y nombrar representantes locales para proseguir las acciones. En noviembre de 1795, el juzgado correspondiente comunicaba a los deudores el decreto de mandamiento, con amenaza de ejecución y embargo de bienes. Cada uno de los acreedores debía recibir 1.359 pesos y fracción, lo que era sin duda una suma muy considerable. ${ }^{49}$

El buceo fue en efecto una rara pero muy productiva vía de ingresos. Ya el lejano hundimiento del navío "Nuestra Señora de la Luz" a mediados del siglo, había generado expectativas y demandado abundante búsqueda.

48 Ibídem, Escribanía de Gobierno y Hacienda, Caja 96, expediente 171.

49 Ibídem, Ex Archivo y Museo Histórico, Caja 239, carpeta 3. 
En 1757 aún faltaban rescatar más de 15.000 pesos del total que componía el registro del buque, y un vecino de Montevideo esperaba hallarlos entre el lastre y la quilla. Laboriosamente consiguió a los dos años un permiso para intentarlo junto con otros colegas..$^{50}$

Los honorarios de los intérpretes parecen haberse hallado entre los más altos en el quehacer regular del puerto. Tal afirmación se deduce de un proyecto de reestructura del servicio de sanidad en 1804. Sus haberes eran allí diez veces más grandes que los correspondientes a los celadores, casi cuadruplicaban a los escribanos y excedían del triple respecto de los fijados a los médicos, ${ }^{51}$ pero no dejaron nunca de ser asignaciones circunstanciales. En julio de 1809, el titulado Pedro Sagrera pidió que se le fijara sueldo, en virtud de estar abandonando para tal desempeño otras atenciones propias de su giro. El Tribunal de Cuentas entendió que las traducciones debían abonarlas las partes interesadas, por lo que el virrey Cisneros no hizo lugar a la solicitud..$^{52}$

Similar deducción puede inferirse acerca de las remuneraciones de los prácticos. Una lancha que en 1813 partió de Asunción con yerba y tabaco, para llegar finalmente a Montevideo, presentaba un verdadero caso de hipertrofia salarial en beneficio de esta clase de especialistas. Capitaneada por su propio dueño, ofrecía pagar 120 pesos por el viaje redondo a "las provincias de abajo", a su baqueano; expresión que sin duda abarcaba aquel concepto, seguramente muy estimado también en la peculiar navegación de los ríos interiores. Esa asignación significaba el doble de la que percibiría el timonel y contenía doce veces las de peones y marineros..$^{53}$

Para continuar con los casos menos generales, en mayo de 1794 se autorizó a ambos médicos el cobro de un arancel por las visitas de los buques. El doctor Schiaffino sostiene que se trataba de un real por pieza en los cargamentos entre 100 y 200 esclavos, que se duplicaba cuando la cantidad era inferior a un centenar; y a lo que debían sumarse otros seis pesos por cada certificación extendida. Al crearse la Junta de Sanidad, variaron los criterios y pasaron a percibir 18 reales por visita; pero como compensación por la caída del valor, las mismas se extendieron a todos los buques..$^{54}$

50 AGNA, División Colonia, Registro de Navíos, Legajo 36, expediente 8.

51 AGN, Archivos Particulares, Caja 246, carpeta 11.

52 AGNA, División Colonia, Tribunales Administrativos, Legajo 25, expediente 805.

53 AGN, Escribanía de Gobierno y Hacienda, Caja 107, expediente 98.

54 Ibídem, Archivos Particulares, Caja 246, carpeta 11. 
A su vez, llama la atención la exigüidad de los salarios percibidos por los escribanos. Apenas superaban los correspondientes a los marineros, y eran menores a carpinteros y calafates. No conocemos, en fin, el nivel que alcanzaban los "sueldos, gratificaciones y cargas de capilla" destinados a los capellanes que "por reglamento" debían embarcarse. Sí está claro que los percibían, y al menos en un caso dieron origen a una enérgica reclamación finalmente desestimada..$^{55}$

Los salarios mejor conocidos corresponden a la ya citada gente de mar, donde se advierten notorias diferencias en favor de los capitanes. A comienzos de siglo ganaban entre 50,60,70 y excepcionalmente hasta 100 ó 120 pesos mensuales, sobre todo en épocas de guerra. Asimismo era posible hallarse con otro tipo de compensaciones, más común en ellos, pero a veces extensiva también a otros tripulantes. Por ejemplo una asignación relativamente baja podía ser nivelada con ciertas concesiones extraordinarias, además de sostenerles hasta la partida o pagarles la totalidad del sueldo aún en ese período de espera. Por lo general se les permitía cargar gratuitamente una parte del buque o cobrar para sí a algún pasajero, y se les prefería en los fletes de retorno.

La acumulación de más de un oficio también elevaba el nivel de los sueldos. Así, era capitán, maestre y primer piloto, el principal de abordo en la fragata española "Nuestra Señora de la Merced", y en una nómina de salarios presentada a las autoridades en mayo de 1811, el titular de esos tres cargos figuraba percibiendo 130 pesos al mes, mientras que las cantidades más próximas pertenecían al segundo piloto y al contramaestre, con ingresos de 50 pesos cada uno. Lo mismo, en una contrata suscrita en 1810 con los dueños de la corbeta "Esperanza", se fijaba al maestre y primer piloto 100 pesos mensuales por ambas funciones. ${ }^{56}$

En general, dentro de la escala de abordo seguía al capitán el segundo piloto. Las proporciones observadas entre ambas responsabilidades mayores en la embarcación, eran de 60 a 40 o de 120 a 90. La tercera remuneración importante correspondía al contramaestre, que se acercaba o igualaba la anterior ( 25 en el primer caso, 90 en el segundo).

En la misma gradación los marineros ganaban bastante menos: 14 y 15 pesos mensuales, mientras que en el caso de cierto viaje arriesgado se

55 AGNA, División Colonia, Hacienda, Legajo 101, expediente 2658, AGN, Ex Archivo y Museo Histórico, Caja 245, carpeta 31. diente 144

56 AGN, Escribanía de Gobierno y Hacienda, Caja 98, expediente 74, y caja 104, expe- 
les otorgaron 28; 25 se prometió a su vez a cuatro que fueron contratados en 1799 para efectuar un difícil e inestable desplazamiento de presa corsaria. El o los cocineros prácticamente igualaban o superaban por escaso margen el nivel de aquéllos. Mientras tanto, los mozos de sala eran por lo general quienes recibían las asignaciones menores, dentro del personal más necesario. Por debajo de esa línea se hallaban agregados, pajes, condestables, etc. Cabe aclarar que todas estas remuneraciones incluían el suministro de la comida. ${ }^{57}$

Existen ejemplos de retribuciones no medidas en forma de salario. Hubo escasos convenios con capitanes para explotar una embarcación "como suya propia", a cambio de la mitad de sus utilidades. ${ }^{58} \mathrm{Al}$ menos en un caso se benefició también así a personal subalterno, que recibiría un porcentaje del flete como "único interés" "en recompensa de (su) industria y trabajo". ${ }^{59}$

La descarga de la fragata presa "Lady Shore" en 1798 representa una muestra de los salarios vinculados con esa clase de operaciones. Necesitó 260 traslados en carretillas, que se abonaron a "dos reales viaje" ${ }^{60}$ en favor de 17 personas distintas, ocupadas durante cuatro días en cumplir de tres a 31 giros, entre el muelle y el arsenal de marina. Al mismo tiempo, insumió 189 jornales de peones a seis reales por trabajador, suma esta última que también se pagó a un maestro carpintero, "por recorrer los cajones que venían malos". Tres pesos recibió un tonelero que acondicionó las barricas afectadas, al igual que el herrero por colocar un candado en el almacén donde se depositaron los efectos. ${ }^{61}$

De acuerdo al reglamento de carretillas de 1811, los cobros de fletes por las operaciones de embarco y desembarco oscilaban entre dos y seis reales, según el tipo y volumen de las cargas movilizadas. Por los acarreos desde el muelle, los almacenes o los extramuros, se percibirían a su vez entre 8 y 16 reales. ${ }^{62}$ En casos de accidentes marítimos acaecidos lejos del

57 Ibídem, Protocolos de Marina, Ventas de embarcaciones, 1805-1806, fols. 7v.-8, y 11v.-12, Escrituras, 1806, fol. 4v, AGNA, División Colonia, Comerciales, Legajo 20, expediente 18.

58 Ibídem, Registro de Escrituras y Fianzas otorgadas, 1808-1812, fols. 275-276 v.

59 Ibídem, Ex Archivo y Museo Histórico, Caja 270, carpeta 53.

60 Exactamente la misma cantidad se pagaba en 1800 por cada uno de los 156 viajes de carretillas demandadas por la descarga de 571 barras de cobre siniestrado en el puerto. El recorrido fue hacia el barracón de marina y el de Berro, y desde éstos a los almacenes del rey. AGNA, División Colonia, Guerra y Marina, Legajo 31, expediente 15.

61 AGN, Escribanía de Gobierno y Hacienda, Caja 35, expediente 51 bis, cuarta pieza, Caja 54, expediente 137.

62 Ibídem, Ex Archivo General Administrativo, Libro 477, fols. 46-48. 
recinto portuario, los carretilleros necesitaban desplazarse con la expectativa de un salario más alto. En agosto de 1794 dos de ellos se repartieron 84 pesos corrientes por doce días de trabajo, a razón de 3.50 diarios. Fueron invertidos en un punto de la costa oeste del río Santa Lucía, donde había varado el bergantín "Vigilancia". Ellos mismos describían las maniobras realizadas, que incluían ida, venida y estancia en el lugar, donde debieron sustituir a las embarcaciones menores "cuando las bajas mares". ${ }^{63}$

Mensualidades de alrededor de 20 pesos y jornales diarios de 2 fueron los más usuales valores con que se retribuyó a los encargados de custodiar y mantener buques. Carpinteros y calafates embarcados cobraban sueldos entre 20 y 25 pesos, superiores por tanto a los correspondientes a los marineros. El citado divulgador de noticias mercantiles percibía a su vez el ingreso de los propios suscriptores que mensualmente aportaban sumas preestablecidas.

Las fórmulas de pago al personal de mar estaban reguladas ordenadamente por el derecho y por la tradición en el caso de las embarcaciones españolas. La norma más invocada en esa materia y otras colindantes fue una real ordenanza de tres de enero de 1755, que contenía un reglamento para la liquidación de soldadas en los navíos mercantes. A su vez la rutina impuso una especie de cultura de anticipos, el primero de los cuales tenía lugar previo a la iniciación de un viaje. Se otorgaban entonces dos sueldos "según costumbre", tal como aparecía textualmente entre otros en un contrato de 1792, donde también se mencionaban futuros adelantos "en el (puerto) de su destino".

El sentido de tales asignaciones era significado en un instrumento similar de 1804, donde se indicaba era "para habilitarse de lo que necesitaran”. En cláusulas de 1812 se ampliaba a su vez el concepto de habilitación, al agregarse que la misma sería "de instrumentos u otras cosas que pueda necesitar". Se empleaba entonces el término "préstamo", que aparece con relativa frecuencia designando este trámite. ${ }^{64}$ Las entregas a cuenta proseguían durante el desarrollo del viaje, en forma de "socorros" ${ }^{65}$ ofrecidos por el propio capitán o por apoderados en los puertos de destino y esca-

63 Ibídem, Ex Archivo y Museo Histórico, Caja 240, carpeta 26.

64 Ibídem, Caja 237, carpeta 5, Caja 257, carpeta 40, Caja 319, carpeta 96.

65 La expresión se empleaba por el capitán de la fragata "La Galga" en noviembre de 1800 para referir los haberes recibidos por la mayor parte de su tripulación. Al guardián, que había pasado a otro buque en la plaza de contramaestre, se le había "socorrido" con 100 pesos, mientras muchos otros se habían conformado con recibir "un socorro". Entre tanto, el capellán Antonio Chico y Arias se había negado a recibir sumas a cuenta, pues reclamaba el pago de la totalidad. Ibídem, Caja 245, carpeta 31. 
las. Los mismos podían suministrarse al propio interesado, a su esposa u otros familiares en los sitios de procedencia. En cambio se hallaba prohibido el pago "de remate" en América, pues se reservaba la rendición final de cuentas para el momento del retorno al lugar de origen, cuando efectivamente concluía el periplo. ${ }^{66}$

Algunos contratos contienen llamativas cláusulas previsoras, del tipo de la que se repetía bastante en documentos de 1803, donde parece sobrevolar el concepto moderno de enfermedad profesional. Se distinguía entre quien "enfermase o (se) lastimase en las funciones del buque", que percibiría sus salarios normalmente, y quienes padeciesen dolencias "buscadas por sí mismos". En otro instrumento suscrito al año siguiente se reservaban los beneficios para el caso de "enfermedad natural o acaecida de los trabajos de a bordo", al contrario de la que fuera "sobrevenida por gustos y pasatiempos voluntarios". ${ }^{67}$

A su vez, en una fórmula de acuerdo hallada por el comandante de Marina en junio de 1811 se arribó a una inusual compensación por despido. Cierto carpintero recibiría la totalidad de salarios vencidos hasta que se prescindió de sus servicios, "y un mes más para ayuda de trasladarse a otra parte" ${ }^{68}$ Esta eventualidad generalmente era prevista en los contratos que por obligación debían labrarse al comienzo de todos los viajes.

El pago de salarios adeudados por el "ejercicio de la mar" aparecía no solamente garantizado, sino también privilegiado. Esa fue la causa más frecuente de las reclamaciones presentadas ante la Comandancia de Marina y el propio Real Consulado de Montevideo. El carácter preferente de los créditos salariales fue sostenido en forma unánime, por lo que debe admitirse que se hallaba muy internalizado a esa altura. Así lo sostuvieron siempre las autoridades, que llegaron a la venta de embarcaciones u otros bienes de los deudores; asimismo fue argumento fundamental de numerosos peticionarios, y a su modo lo reconocieron también los demandados.

66 El capitán de la fragata mencionada arriba explicaba este asunto en 1800: "El ser pagado de remate ningún individuo del roll de España, en América, está prohibido, pues se previene en el mismo roll que no se proceda a hacer pagamento de soldadas hasta que se haya pasado revista a todos los individuos por aquel ministro principal de marina de la provincia de Cádiz o bien por aquel en donde se dé por concluido el viaje". A su vez, entre las causas que citaban los capitanes de varios buques detenidos en 1805 por la guerra con Gran Bretaña para no pagar a los pilotos sus haberes vencidos, mencionaban: "Que está prohibido por ordenanza que la gente de mar se pague de remate en Indias". Ibídem, Caja 264, carpeta 47.

67 Ibídem, Protocolos de Marina, Fianzas de buques, 1803-1804, fol. 71v., Ex Archivo y Museo Histórico, Caja 257, carpeta 40.

68 Ibídem, Ex Archivo y Museo Histórico, Caja 306, carpeta 84. 
Cuando el adquirente de una polacra española vendida para satisfacer deudas de su propietario, solicitaba prórroga en 1813, los síndicos del juicio resaltaban ese privilegio, "por pertenecer a soldadas de la tripulación". "No deb(ía)n admitir espera ninguna", pues sus acreedores habían "expu(esto) sus vidas en la navegación para el sustento de sus familias que tanto anhela(ba)n de socorrer". ${ }^{69}$

Como se ha visto, el puerto generó variada ocupación, origen a su vez de un reparto de riqueza desigual y de escasas garantías. No obstante, el concepto cardinal de la redistribución parece haber sido a grandes rasgos el de la justicia. Efectivamente, en general ganaron más quienes tuvieron mayores responsabilidades, audacia y preparación.

Después de acumular las informaciones precedentes, no parece razonable dudar acerca del papel dinamizador de los servicios portuarios en Montevideo. Tanto el capital como el trabajo obtuvieron empleo y beneficios, aún con las múltiples salvedades y desequilibrios que se han expuesto.

Obviamente, intervinieron también diversos imponderables, entre ellos el enrarecimiento de la situación política; la escasez y providencialidad de ciertas intervenciones, como las de los buzos ocasionalmente tan bien retribuidos; o la desmedida concurrencia de algunos oficios recompensados con excesiva cortedad en virtud de la antigua ley de oferta y demanda.

La mayor parte de los beneficios confluyó sin duda en el sector comercial. De sus planteles salieron todos los abastecedores, por ejemplo, en número necesariamente mayor al de los sucesivos titulares del asiento. Al mismo tiempo, la masa de salarios pagados a residentes y transeuntes tenía como destino más probable los propios mostradores.

La notoria ruina de Batlle y Carreó fue a su vez la de la coyuntura. Muchos perdieron en esos momentos, porque toda la estructura económica se hundió y los arrastró consigo.

69 Ibídem, Escribanía de Gobierno y Hacienda, Caja 106, expediente 72. 